\title{
Numerical Study of Distribution Temperature and Air Flow Velocity at Closed Type Chicken Coop for Capacity of 15,500 Chicks with Opening 1 Inlet and 4 Exhaust
}

\author{
Nia Nuraeni Suryaman*, Udin Komaruddin, Arry Hutomo, Martoni \\ Department of Indonesia Mechanical Engineering, Widyatama University, Indonesia
}

Copyright $\bigcirc 2019$ by authors, all rights reserved. Authors agree that this article remains permanently open access under the terms of the Creative Commons Attribution License 4.0 International License

\begin{abstract}
Uniformity of temperature in a room is often encountered in various purposes. This study presents the results of modeling the temperature and airflow in the chicken coop. A problem to be solved in this research is how to design the chicken coop in order to produce temperature uniformity. Thus, the objectives are to build a chicken coop dimensional model of $96 \times 12 \times 2 \mathrm{~m}$ with a capacity of 15,500 chicks. Modeling results analysis using CFD (Computational Fluid Dynamics). The stage of completion to meet the above objectives is by measuring the dimensions of the chicken coop. The next data to be obtained are temperature and air velocity to determine the boundary conditions. Some of the above parameters are used to validate chicken coop design. Modeling conducted using CFD methods with temperature and air velocity as boundary conditions. The modeling results showed that the average temperature in the chicken coop is adequate as an ideal temperature standard for chicken coop. Temperature uniformity is obtained by variation of the exhaust opening 4.
\end{abstract}

Keywords Heating Chicken Coop, CFD, Temperature Distribution and Air Flow Velocity, Numerical and Experimental Study

\section{Introduction}

Indonesia's population continues to increase from year to year. In 2015 there were 252 million people, thus the need for food is always increasing. One of these food needs is chicken meat. Seeing the large requirements of broiler chicken meat, broiler breeders develop their businesses in various ways, one of them has a comfortable chicken coop to produce quality chicken. The things that affect the quality of chicken meat are genetic factors and environmental factors. Chicken genetic factors are factors that exist in chickens since they are still in the egg, good genetic factors can be seen from the Day-Old Chick (DOC). Chicken environmental factors are factors that affect outside the chicken's body.

Air temperature in Indonesia varies in each region. Chicken coop is located at Tasikmalaya has temperature between $25-30^{\circ} \mathrm{C}$ during the day and $18-20^{\circ} \mathrm{C}$ at night. DOC broilers require temperatures between $32-35^{\circ} \mathrm{C}$. One effort to condition the temperature in the chicken coop is to use a heating device. In this study will use incandescent lamps as heating devices. The selection of incandescent lamps as a heating device is because the cost is cheaper than other heating devices but produces a lot of heat. The temperature produced by the lamp must be distributed evenly to the entire chicken coop. So that the use of lamps as a heating device can reduce investment costs but does not reduce the quality of chicken produced.

This research will only analyze the conditions of temperature and air velocity distribution, use of incandescent lamps as a 100 Watt power heater, temperature analysis inside the chicken coop is done at the age of broiler chickens the first day until the 14th day, using one variation of the inlet opening, the size of the chicken coop is $96 \mathrm{~m} \mathrm{x} 12 \mathrm{m \times 2} \mathrm{m}$ and this research is an extension of previous research. Therefore, the formulation of this research is how to design a chicken coop with a capacity of 15,500 to have a uniform distribution of temperature and air velocity in the chicken coop.

The purpose of this study was to analyze the conditions of temperature and air velocity distribution in chicken coops using CFD. The output to be produced in this study is the design of a chicken coop that has a uniform 
temperature in it and graphs the distribution of temperature and air velocity. The benefits obtained from this study are simulation programs on CFD can reduce the cost of design and construction and avoid the development of chicken coop by trial and error. In this study, flow conditions and temperature distribution will be observed numerically using Computational Fluid Dynamics (CFD). Determination of boundary conditions and fluid flow for this CFD method based on the actual data obtained at the time of the survey to the chicken coop.

\section{Literature Study}

\subsection{Characteristics of Chicken}

Because of the need for large broilers, quality chicken is needed. The things that affect the quality of chicken meat are genetic factors and environmental factors. Chicken genetic factors are factors that exist in chickens since they are still in the egg, good genetic factors can be seen from the Day-Old Chick (DOC). Examples of good genetic factors in DOC are hatching weight between 35-40 grams/head, bright eyes, can stand and be agile, no defects, have a loud voice. ${ }^{(4)}$ Chicken weight at harvest time is 1.8 $\mathrm{kg}$ on the 30 th day and $2 \mathrm{~kg}$ on the 35 th day. ${ }^{(9)}$ Examples of chicken environmental factors are feed consumption, temperature and air velocity inside and outside the chicken coop.

\subsection{Effect of Temperature on Chickens}

Broiler chicken is a type of animal that will maintain its body temperature so that it remains relatively stable in various environmental conditions. This causes broiler chickens produce heat from their bodies. The heat comes from body weight, food and drinks consumed and environmental conditions. There are two types of heat released by broiler chickens:

a. Sensible heat, which is heat released by the body due to the temperature difference between the body and the environment.

b. Latent heat, which is heat released by the body during important events, because chickens do not have sweat glands. Latent heat will be released by the chicken if the ambient temperature is very high.

Chicken heat needs vary by age. The beginning of Day Old Chick's life (DOC) requires a high brooder heat. As the age of the chicken increases, the heat demand will decrease. ${ }^{(7)}$ Table 1 is a standard table of temperature and humidity for chickens based on age. ${ }^{(6)}$ Table 2 is the ideal temperature table for chickens in the Mangunreja chicken coop, Tasikmalaya.

Temperature is a climate factor that affects the heat production of broiler chickens. The influence of environmental conditions around the chicken will have an impact on the productivity of the chicken. If the ambient temperature is too high or low, the chicken will experience heat stress or stress which affects the death of the chicken.

Table 1. Temperature and Humidity Standards

\begin{tabular}{|c|c|c|c|c|}
\hline \multirow{2}{*}{$\begin{array}{l}\text { Age } \\
\text { (days) }\end{array}$} & \multicolumn{2}{|c|}{ Brooding temperature } & \multirow{2}{*}{$\begin{array}{c}\text { Room } \\
\text { temperature }\end{array}$} & \multirow{2}{*}{$\begin{array}{c}\text { Relative } \\
\text { humidity } \\
\text { optimum-maximum } \\
\text { in } \%\end{array}$} \\
\hline & $\begin{array}{l}\text { At the edge of the } \\
\text { brooders }\end{array}$ & $\begin{array}{l}\text { At } 2-3 \mathrm{~m} \text { from the } \\
\text { brooders }\end{array}$ & & \\
\hline $0-3$ & $35^{\circ} \mathrm{C}$ & $29-28^{\circ} \mathrm{C}$ & $33-31{ }^{\circ} \mathrm{C}$ & $55-60$ \\
\hline $4-7$ & $34{ }^{\circ} \mathrm{C}$ & $28-27^{\circ} \mathrm{C}$ & $32-31{ }^{\circ} \mathrm{C}$ & $55-60$ \\
\hline $8-14$ & $32^{\circ} \mathrm{C}$ & $27-26^{\circ} \mathrm{C}$ & $30-28^{\circ} \mathrm{C}$ & $55-60$ \\
\hline $15-21$ & $29^{\circ} \mathrm{C}$ & $26-25^{\circ} \mathrm{C}$ & $28-26^{\circ} \mathrm{C}$ & $55-60$ \\
\hline $22-24$ & & $25-23^{\circ} \mathrm{C}$ & $25-23^{\circ} \mathrm{C}$ & $55-65$ \\
\hline $25-28$ & & $23-21^{\circ} \mathrm{C}$ & $23-21^{\circ} \mathrm{C}$ & $55-65$ \\
\hline $29-35$ & & $21-19^{\circ} \mathrm{C}$ & $21-19^{\circ} \mathrm{C}$ & $60-70$ \\
\hline After 35 & & $19-17^{\circ} \mathrm{C}$ & $19-17^{\circ} \mathrm{C}$ & $60-70$ \\
\hline
\end{tabular}

Source: Isa Brown Manual Management 
Table 2. Ideal temperature for chickens

\begin{tabular}{|c|c|}
\hline Age of Chicken (day) & Temperature of Chicken Coop $\left({ }^{\circ} \mathbf{C}\right)$ \\
\hline $\mathbf{0 - 3}$ & $32-35$ \\
\hline $\mathbf{4 - 7}$ & $31-34$ \\
\hline $\mathbf{8 - 1 4}$ & $30-31$ \\
\hline $\mathbf{1 5}-\mathbf{2 1}$ & $29-30$ \\
\hline $\mathbf{2 2}-\mathbf{2 8}$ & $23-26$ \\
\hline $\mathbf{2 8}$ & 24 \\
\hline
\end{tabular}

Source: Mangunreja Chicken Coop, Tasikmalaya

\subsection{Chicken Coop Heating Devices}

The temperature in the chicken coop can be conditioned by the use of heating devices. The heating device used in this study is a lamp. The types of lamps on the market are incandescent, TL/fluorescent lamps, halogen lamps and LED lights. The type of lamp used in this study is the type of incandescent lamp. Compared with other types of heating equipment, the use of coal as a heating device requires a very large cost. The use of gas is cheaper compared to coal, but the fluctuations in LPG prices and their availability in Indonesia pose their own constraints. The use of firewood is cheaper but produces smoke that is not good for chicken growth. Another advantage of using lamps is the easy installation and operation.

\subsection{Air Conditioning in Chicken Coop}

The temperature in the chicken coop is influenced by the dimensions of the coop, the number of livestock, the temperature of the outside environment, solar radiation, ventilation systems and air velocity. The design of the chicken coop itself affects the temperature distribution inside, such as the position of the wall against sunlight, ventilation openings systems, cage roofs, and roof and wall enclosure material and so on.

Ventilation in the chicken coop building functions to control temperature, air circulation so that the ideal conditions inside the cage are fulfilled. Ventilation in the chicken coop building is in the form of exhaust. This exhaust can be adjusted so that when the temperature inside the cage is too high it can open and circulate the air. The air velocity inside the cage must also be regulated and maintained to produce a comfortable environment in the cage. According to Hasbi Mubarok's research, the average air velocity in the cage generated from the simulation results is $2.28 \mathrm{~m} / \mathrm{s}^{(5)}$

Method for obtaining air conditioning in the chicken coop is by measuring in the field. Measurements made in the field are measurements of temperature and air velocity.
The measurements were carried out at several points: in the chicken coop, exhaust, the chicken coop entrance, the environment outside the chicken coop. Measurement of outlet and inlet area is measured on the area of the exhaust and the entrance of the chicken coop.

\subsection{Energy Balance of Chicken Coop}

Energy balance is the application of the Law of Thermodynamics I; changes that occur in the system during the process are the same as the difference between the total energy in and the total energy out of the system during the process. ${ }^{(8)}$

$$
\left(\begin{array}{c}
\text { Change in The Total } \\
\text { Energy of the System }
\end{array}\right)=\left(\begin{array}{c}
\text { Total Energy } \\
\text { Entering the System }
\end{array}\right)-\left(\begin{array}{c}
\text { Total Energy } \\
\text { Leaving the System }
\end{array}\right)
$$

Or

$$
\Delta E_{\text {system }}=E_{\text {in }}-E_{\text {out }}
$$

Energy that enters the chicken coop comes from the chicken coop entrance in the form of temperature and air velocity. Energy coming out of the chicken coop from the exhaust is in the form of temperature and air velocity. Changes that occur in the chicken coop come from heat released by chickens and lamps. In addition, the energy wasted by the heat transfer on the wall affects the energy changes in the chicken coop.

\subsection{Numerical Studies Using CFD}

Computational Fluid Dynamics (CFD) is an analysis system that includes fluid flow, heat transfer, and phenomena such as chemical reactions based on computer-based simulations. Completion of complex fluid flow problems can be done by using CFD by identifying and formulating fluid flow. Fluid flow classification is compressible \& incompressible, steady \& unsteady, laminar \& turbulent. Identification of fluid flow needs to be done before analyzing. ${ }^{(3)}$

The numerical discretization technique used in CFD is Finite Element Method (FEM), Finite Difference Method (FDM) and Finite Volume Method (FVM). CFD generally uses numerical FVM discretization techniques. ${ }^{(1)}$ Completion of the equations contained in CFD requires measurement data as boundary conditions. The boundary conditions in the inlet, outlet, wall and other conditions must have a reference in solving the equation in CFD. The closer the boundary conditions data with the data obtained in the field, the better and accurate the results will be obtained. ${ }^{(2)}$ Figure 1 is the flow of the CFD process. ${ }^{(3)}$ 


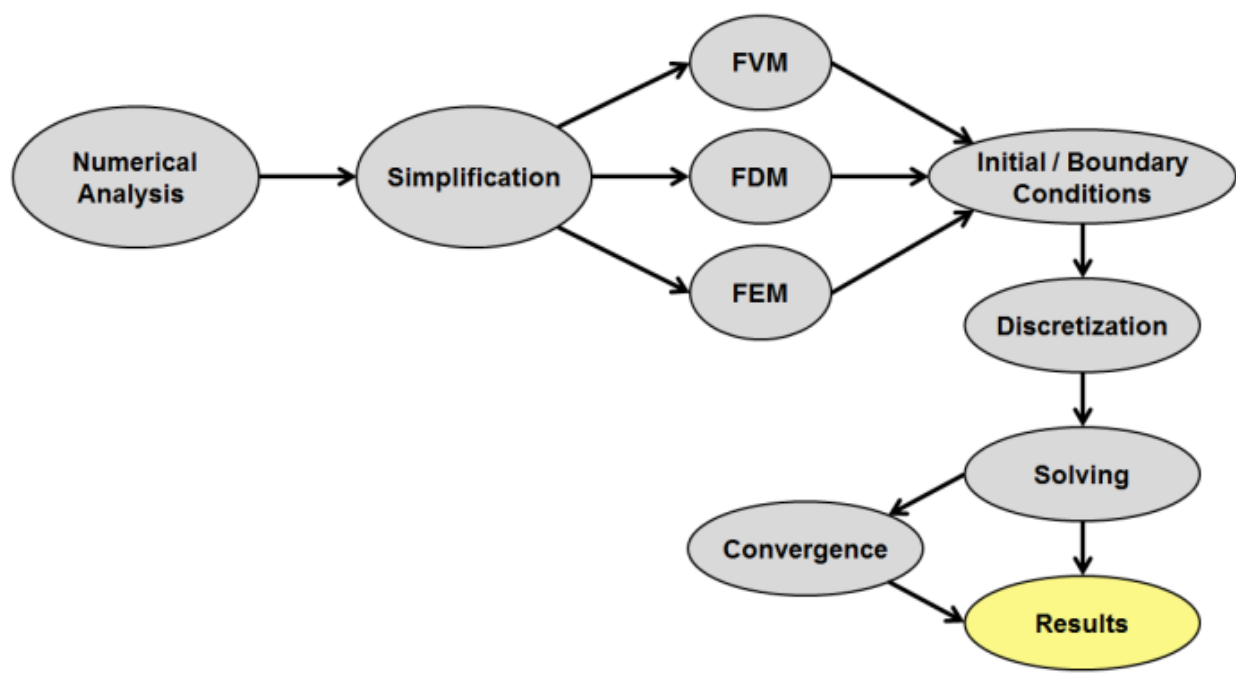

Figure 1. CFD Flow Process

\section{Research Methodology}

1) Conduct Data Collection Conducted by Assessing Theories and References that Support Research

2) Survey for Initial Data Collection (Boundary Condition)

This study conducted an experimental test by measuring temperature data. The location of this research is in Mangunreja District, Tasikmalaya, West Java. The data obtained are:

- Dimensions of chicken coop: $96 \times 12$ × 2 m

- Measurement of temperature and air velocity:

Table 3. Measurement data

\begin{tabular}{|c|c|c|}
\hline Position & Temperature $\left({ }^{\circ} \mathrm{C}\right)$ & Air Flow Velocity $(\mathrm{m} / \mathrm{s})$ \\
\hline inlet & 29 & 2.8 \\
\hline outlet & 30.28 & 5.78 \\
\hline
\end{tabular}

- Material of chicken coop:

Table 4. Material of Chicken Coop

\begin{tabular}{|l|l|}
\hline Position & Material \\
\hline Right side wall & polystyrene \\
\hline Left side wall & polystyrene \\
\hline Front wall & brick \\
\hline Back wall & brick \\
\hline Roof & brick \\
\hline Floor & brick \\
\hline
\end{tabular}

3) Preparation and Analysis of Energy Balance

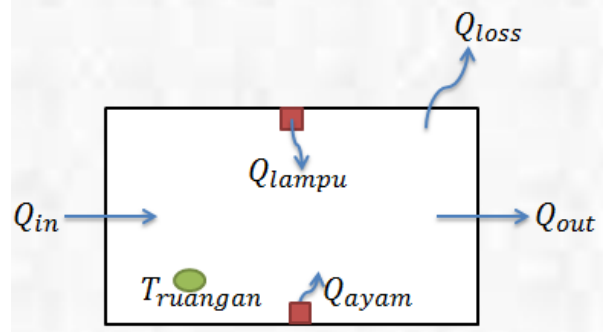

Figure 2. Energy Balance of Chicken Coop
From the picture above, energy balance can be analyzed as follows:

$$
Q_{\text {in }}+Q_{\text {gvam }}+Q_{\text {lampu }}-Q_{\text {loss }}-Q_{\text {out }}=0
$$

$Q_{\text {ayam }}$ is a sensible heat released from the chicken's body. The chicken sensible heating value can be obtained from Figure 3. In the picture, the chicken sensible heat depends on the weight of the chicken or the age of the chicken. The heavier the weight of the chicken, the greater the sensible heat released.

In the chicken sensible heat table there are several environmental conditions and different room conditions. The selected chicken sensible heating value is the sensible heating value of the chicken which has the same environmental and room conditions or is close to the research conditions. The chicken sensible heat obtained is shown in Figure 3.

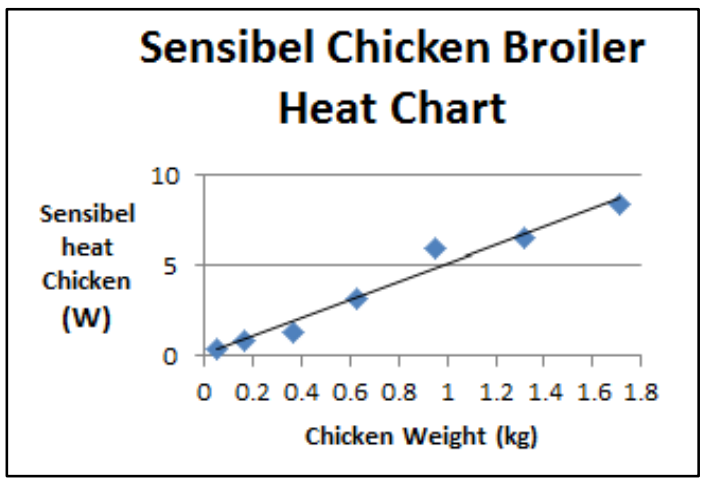

Figure 3. Sensible Chicken Heat function of Chicken Weight

4) Determine the Position of Air Temperature and Air Flow Velocity Measurement

The position of measuring temperature and air speed is set according to the following picture: 


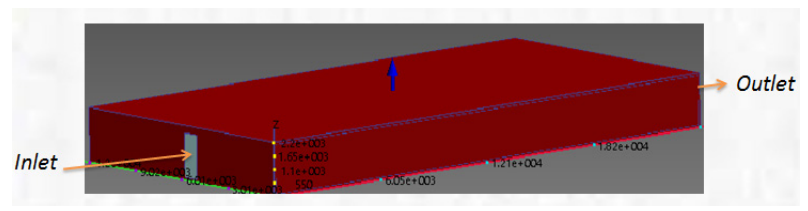

Figure 4. Position of Inlet and Outlet

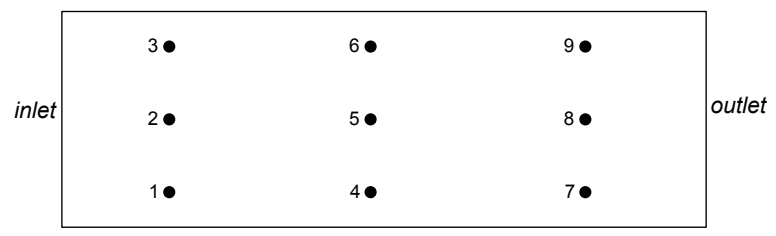

Figure 5. Position of Measurement inside the Chicken Coop

5) Perform Simulation and Validation

Simulation and analysis were using Autodesk CFD. The data needed to conduct CFD simulations is done by field measurements and calculations using existing theories. The measurement data in the field includes the temperature and air velocity as the boundary condition, the size of the cage, the size of the entrance, the exhaust size, the size of the "cage area" ( 1 cage area $=6 \times 12 \mathrm{~m})$ and the cage material. The measurement data in the field includes the temperature and air velocity as the boundary condition, the size of the cage, the size of the entrance, the exhaust size, the size of the cage area $(1$ area $=6 \times 12 \mathrm{~m})$ and the chicken coop material. The calculation data is chicken sensible heat, lamp heat and heat transfer coefficient on the wall.

The assumptions used in the simulation are:1) air moves in steady conditions; 2) air flow is considered turbulent; 3 ) environmental air is considered constant.

Validation is to compare the measurement results with the simulation results. Validation in this study is displayed with Standard Error (SE). Standard error uses equation (3). Standard deviation values for air temperature and velocity distribution using equation (4).

$$
S E=\frac{s}{\sqrt{n}}
$$

$\mathrm{SE}=$ Standard Error

$\mathrm{s}=$ Standard Deviation

$\mathrm{n}=$ number of points

$$
s=\sqrt{\frac{\sum\left(t_{p}-t_{c}\right)^{2}}{n-1}}
$$

$t_{p}=$ The value of temperature / air velocity at the measurement point observed

$t_{c}=$ Value the temperature / air velocity at the midpoint of measurement in the chicken coop

$\mathrm{n}=$ Number of measurement points

\section{Results and Discussion}

\subsection{CFD Simulation Results}

Analysis of temperature distribution was carried out with the condition of the cage filled with 15,500 chickens. The chicks are placed on the $5^{\text {th }}$ and $6^{\text {th }}$ "cage area", which is at a distance of $25 \mathrm{~m}$ from the entrance of the room. Field measurements conducted on May 29, 2015, at $2 \mathrm{pm}$. Environmental temperature measured $29^{\circ} \mathrm{C}$ and air speed $3.6 \mathrm{~m} / \mathrm{s}$. The temperature of the chicken coop inlet measured $29^{\circ} \mathrm{C}$ and the air velocity was $2.8 \mathrm{~m} / \mathrm{s}$.

Simulation using Autodesk CFD is done using an experimental design. The parameters contained in the design of the experiment are: 1) size of "cage area"; 2) exhaust; 3) number of inlets; 3) lamp position; 4) number of lamps. The following table is a CFD simulation experiment design.

The criteria for a good chicken coop are those that have a constant and uniform temperature and have good air circulation. For the age of chickens on day 1, the simulation results of opening 1 inlet for air velocity are shown in Figure 5, while for the temperature simulation image shown in Figure 6. The resulting average velocity is $0.253 \mathrm{~m} / \mathrm{s}$ with an average temperature of $34.139^{\circ} \mathrm{C}$. The standard error in this simulation is $0.015 \mathrm{~m} / \mathrm{s}$ for air velocity and $0.5^{\circ} \mathrm{C}$ for temperature.

Table 5. Simulation Experiment Design

\begin{tabular}{|c|c|c|c|c|}
\hline $\begin{array}{c}\text { size of "cage } \\
\text { area" }\end{array}$ & Exhaust & $\begin{array}{c}\text { number } \\
\text { of } \\
\text { inlets }\end{array}$ & $\begin{array}{c}\text { lamp } \\
\text { position }\end{array}$ & $\begin{array}{c}\text { number of } \\
\text { lamps }\end{array}$ \\
\hline 2 & 1 & 1 & $\begin{array}{c}\text { Placed } \\
\text { before } \\
\text { chicken }\end{array}$ & 200 unit \\
\hline 5 & 2 & & & \\
\hline 7 & 4 & & & \\
\hline 10 & & & & \\
\hline
\end{tabular}

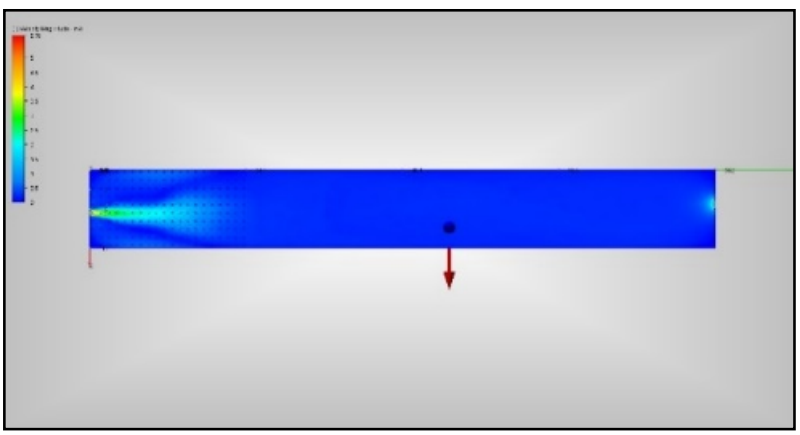

a) 1 exhaust open 


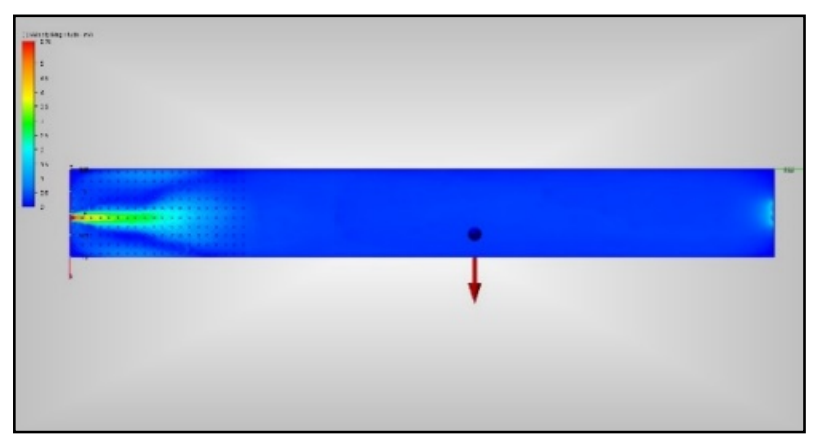

b) 2 exhaust open

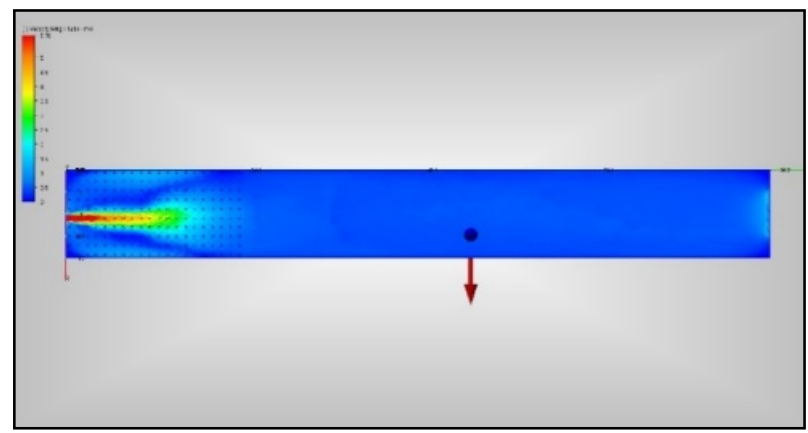

c) 4 exhaust open

Figure 6. Air Velocity Simulation Results for 1 Inlet Openings for Chicken Age Day 1

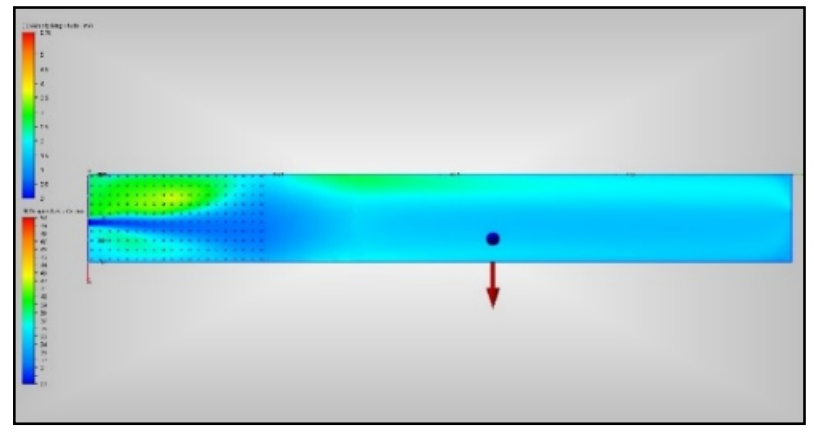

a) 1 exhaust open

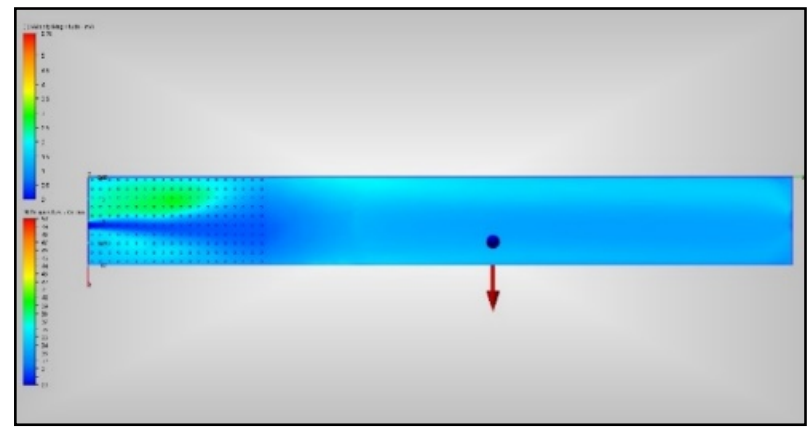

b) 2 exhaust open

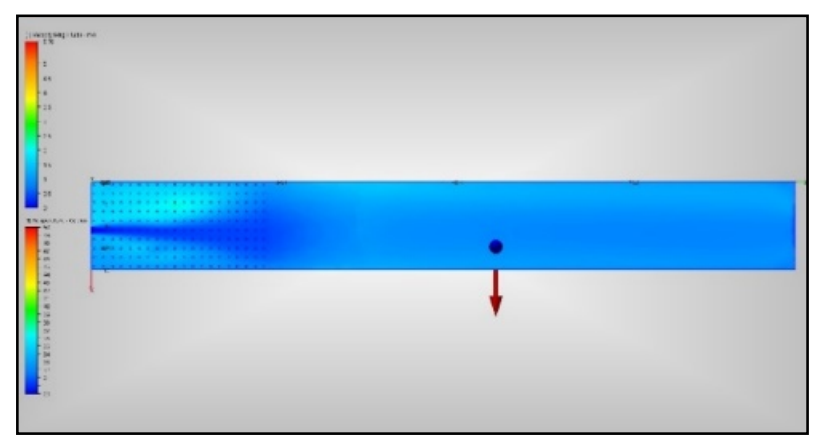

c) 4 exhaust open

Figure 7. Results of 1 Inlet Opening Temperature Simulation for Chicken Age Day 1

Figure 8 shows a graph of the relationship between standard error, age of chicken and variation of inlet and outlet openings for temperature inside the cage. Openings in 1 inlet and 4 outlets shown in the graph have the lowest standard error value. In addition, the standard error changes each day show a relatively straight line. This shows that the variation in these openings has a relatively stable or uniform temperature in the chicken coop. For variations in opening 1 inlet and 1 exhaust, the standard error value is getting higher every day. This shows that the variation in this opening has a non-uniform temperature in the chicken coop.

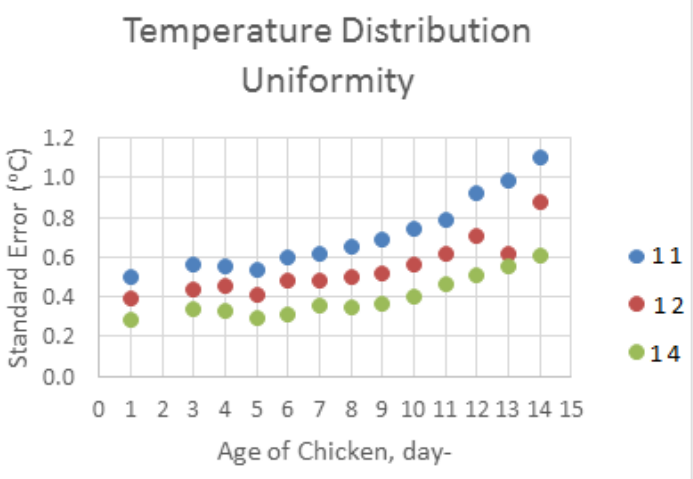

11: 1 inlet, 1 exhaust; $12: 1$ inlet, 2 exhaust; $14: 1$ inlet, 4 exhaust

Figure 8. Graph of Uniformity of Temperature Distribution

Figure 9 shows a graph of the relationship between standard error, age of chicken and variation of inlet and exhaust openings for air velocity in the cage. The opening variation of 1 inlet and 4 exhausts shows a high standard error. This shows that for variations in this opening it has an uneven air velocity. But this result shows that in this variation openings have good air circulation. The greater the weight of the chicken indicated by the age of the chicken, it requires good air circulation but with a stable cage temperature. Chicken coop that has good air circulation means that there is a difference in air velocity at each measurement point. 


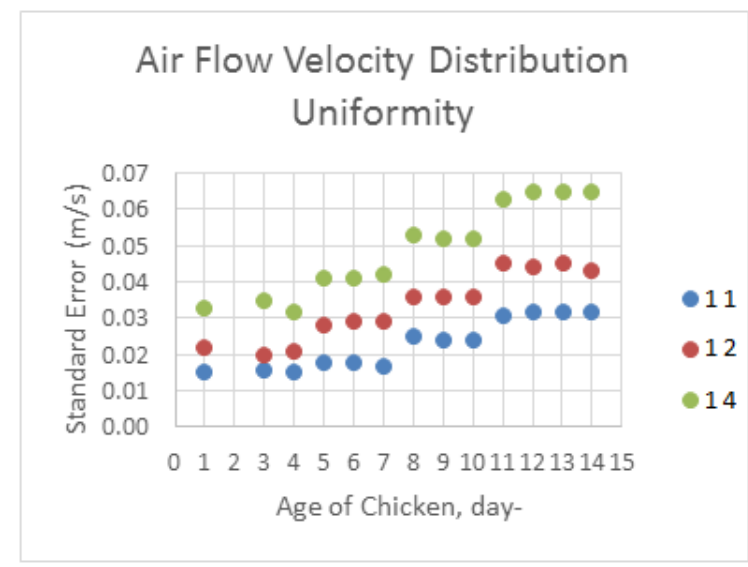

11: 1 inlet, 1 exhaust; $12: 1$ inlet, 2 exhaust; $14: 1$ inlet, 4 exhaust

Figure 9. Graph of Uniformity of Air Flow Velocity Distribution

\subsection{Validation Results of CFD}

Validation of temperature distribution in the chicken coop is done by comparing the measurement results with the simulation results. Validation was carried out in the chicken coop as many as nine points. Table 6 shows the standard error of temperature and air velocity for the age of chickens on day 1 with 1 exhaust open. Figure 9 is a temperature validation graph and Figure 10 is an air velocity validation graph.

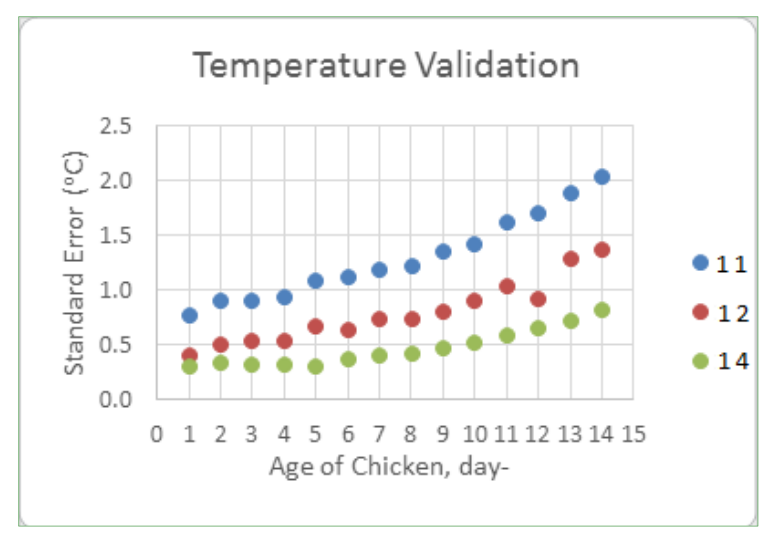

11: 1 inlet, 1 exhaust; $12: 1$ inlet, 2 exhaust; $14: 1$ inlet, 4 exhaust

Figure 10. Temperature Validation Graph

\section{Air Flow Velocity Validation}

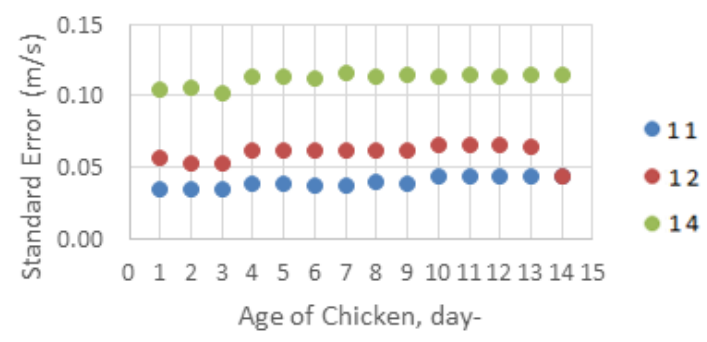

1 1: 1 inlet, 1 exhaust; $12: 1$ inlet, 2 exhaust; $14: 1$ inlet, 4 exhaust

Figure 11. Air Flow Velocity Validation Graph

Table 6. Standard Error for 1st Day Chicken Age, 1 Exhaust Open

\begin{tabular}{|c|c|c|c|c|c|c|}
\hline \multirow{2}{*}{ Measurement point } & \multicolumn{2}{|c|}{ Air Flow Velocity $(\mathrm{m} / \mathrm{s})$} & \multicolumn{2}{|c|}{ Temperature $\left({ }^{\circ} \mathrm{C}\right)$} & \multirow{2}{*}{$\mathrm{d}^{2}$} \\
\cline { 2 - 3 } \cline { 5 - 7 } & Measurement & Simulating & & Measurement & Simulating & \\
\hline 1 & 0.2 & 0.3 & 0.010 & 32 & 32.25 & 0.063 \\
\hline 2 & 0.3 & 0.35 & 0.003 & 32 & 34.6 & 0.160 \\
\hline 3 & 0.1 & 0.21 & 0.012 & 32.5 & 34.75 & 3.063 \\
\hline 4 & 0.1 & 0.225 & 0.016 & 33 & 34.1 & 1.210 \\
\hline 5 & 0.2 & 0.25 & 0.003 & 33 & 36.4 & 8.410 \\
\hline 6 & 0.1 & 0.23 & 0.017 & 33.5 & 34.3 & 5.290 \\
\hline 7 & 0.3 & 0.23 & 0.005 & 32 & 33.9 & 8.410 \\
\hline 8 & 0.4 & 0.26 & 0.020 & 31 & 35.7 & 13.690 \\
\hline 9 & 0.2 & 0.22 & 0.000 & 32 & & 2.328 \\
\hline Standard deviation & & & 0.103 & & & 0.776 \\
\hline Standard error & & & 0.034 & & & \\
\hline
\end{tabular}




\section{Conclusions}

a. The simulation results for the average temperature in the chicken coop are suitable with the standard ideal temperature requirements for chicken coops (Saudi et al., 2019).

b. Temperature uniformity in the chicken coop is obtained by variations in the opening of 1 inlet and 4 exhausts.

\section{REFERENCES}

[1] Autodesk Education Community, (2011), "Fluid Flow: Application of Numerical Methods", Autodesk Education Community

[2] Autodesk Education Community, (2011), "Fluid Flow: Establishing Boundary Conditions", Autodesk Education Community

[3] Autodesk Education Community, (2011), "Fluid Flow: Overview of Fluid Flow Analysis", Autodesk Education Community

[4] Ay Irfan, (2013), "Memilih DOC Ayam Broiler yang Baik", http://hargadoc.blogspot.com/2014/03/memilih-doc-ayambroiler-yang-baik.html, accessed on 1 Juni 2015

[5] Hasbi Mubarok Suud, Kudang Boro Seminar, (2009), "Simulation of Airflow Pattern and Temperature Distribution at Closed House System Chicken House Using Computational Fluid Dynamics", page. 1, Bogor Agricultural Institute, Bogor

[6] Ismail, A., Abd El Salam, A. L., \& Kassem, A. K. (2016). Web Service Composition for E-Commerce Web Application. Review of Computer Engineering Research, 3(1), 13-24.

[7] Mei Sulistyoningsih, (2004), "Berbagai Respon Fisiologis Ayam Broiler Akibat Temperatur Lingkungan”, Lontar Scientific Magazine, IKIP PGRI Semarang Press

[8] Michael J. Moran, (2003), "Introduction to Thermal Systems Engineering: Thermodynamics, Fluid mechanics and Heat Transfer", hal. 44, John Wiley \& Son, Inc., US

[9] Yadi, Interview, (2015), "Explanation of Chicken Weight and Chicken Cage Area", Mangunreja Chicken Coop Kab. Tasikmalaya

[10] Saudi, M.H.M., Sinaga, O., Roespinoedji, D., \& Jabarullah, N.H. (2019) Industrial, Commercial and Agricultural Energy Consumption and Economic Growth Leading to Environmental Degradation, Ekoloji, 28 (107), 299 - 310. 